$\begin{gathered}\text { Ana Dili Eğitimi Dergisi } \\ \text { Journal of Mother Tongue Education } \\ \text { www.anadiliegitimi.com }\end{gathered}$
Geliş/Received: 31.10 .2018 Kabul/Accepted:03.12.2018

\title{
Yabancı Dil Olarak Türkçe Öğrenen Bireylerin Yaptıkları Sözdizimi Hatalarının İncelenmesi
}

\author{
Zeynep Zeliha BAYAZIT*
}

Öz

Alan yazında özellikle de yabancı dil olarak Türkçeyi öğrenen ve anadili İngilizce olan bireylerin iki dil arasında daha çok karşılaştırma yaptıkları, dahası çoğu zaman da kendi anadillerinde düşünerek sözdizimsel hatalar yaptıkları belirtilmektedir. Bu anlamda yabancı dil olarak Türkçe öğretiminde sorun odaklı yaklaşımlara yönelik araştırmalar oldukça önem kazanmaktadır. Sorun odaklı yaklaşımlardan biri olan hata analizi yöntemi, ikinci dil öğrenme sürecinin incelenmesi açısından oldukça önemli ipuçları vermektedir. Bu nedenle bu çalışmada, anadili İngilizce olan ve Türkçeyi yabancı dil olarak öğrenen bireylerin en çok yaptıkları sözdizimsel hataları, hata analizi ve karşılaştırmalı analiz bulgularından yararlanarak belirlemek amaçlanmıştır. Çalışma, Indiana Üniversitesi Turkish Flagship Programında yabancı dil olarak Türkçe öğrenen ve anadili İngilizce olan A2 düzeyindeki 30 öğrenci üzerinde yürütülmüştür. Öğrenci hatalarını saptamak için öğrencilere "Sorulara Cevap Verme", "Boşluk Doldurma" ve "Tümceyi Yeniden Yazma" bölümlerinden oluşan bir test uygulanmıştır. Çalışma sonunda öğrencilerin daha çok biçimbilimsel ve dilbilgisel yanlışlardan kaynaklı sözdizimi hataları yaptıkları görülmüştür.

Anahtar Kelimeler: Türkçe, yabancı dil olarak Türkçe, sözdizimi, dilbilgisi, hata analizi

The Investigation of Syntax Errors by Learners of Turkish as a Foreign Language

\begin{abstract}
In the literature, especially it is stated that individuals who learn Turkish as a foreign language and native speakers of English make more comparisons between two languages, and they make more often syntactic errors by thinking in their mother tongue. In this sense, studies on problemoriented approaches in teaching Turkish as a foreign language become important. The error analysis method, which is one of the problem-oriented approaches, provides an important clues for the second language learning process. Therefore, in this study, it is aimed to determine the most common syntactic errors by English native speaker learners of Turkish as a foreign language by using error analysis and comparative analysis findings. This study was conducted on 30 native speakers of English who are A2 level students at Indiana University Program of Turkish Flagship. In order to determine student errors, the test consisting of "Answering to Questions", "Gap-Filling" and "Re-writing the Sentences", was implemented. At the result, it was seen that students mostly made syntax errors which kind of morphological and grammatical.
\end{abstract}

Keywords: Turkish, Turkish as a foreing language, syntax, grammer, error analysis

* Dr., Ankara Üniversitesi Eğitim Bilimleri Fakültesi Sosyal Bilgiler ve Türkçe Eğitimi Bölümü, e-posta: zeliha.bayazit@gmail.com, ORCID: 0000-0001-5307-1791 


\section{Giriş}

Düşüncelerin aktarılmasında en önemli araç olan dildeki birimler rastgele bir araya getirilmemektedir. Nasıl ki iletişimi sağlamanın belli koşulları varsa, bu iletişimde kullanılacak tümceleri oluşturan sözcükleri bir araya getirmenin de belli koşulları bulunmaktadır. İşte bu koşullar sözdizimi adı verilen dilbilim dalı tarafından belirlenmekte ve incelenmektedir.

Türkçe ve diğer pek çok dilde tümcenin anlamının belirlenmesinde sözcüklerin o dilin kurallarına göre düzenlenmesi çok önemli bir faktördür. Nitekim bir dilin çözümlenmesi bütünüyle olmasa bile büyük ölçüde sözdizimi sorunlarının açıklığa kavuşturulmasına bağlıdır. Bu nedenle sözdizimi çalışmaları günümüzde de güncelliğini korumaktadır (Atabay, Özel ve Çam, 1981).

Anadil konuşucuları, dilin sözdizim kurallarını bilinçaltı yoluyla, kuralların varlığından habersiz olarak edinmektedirler; ancak söz konusu ikinci dil öğrenicileri olduğunda, durum değişmektedir. Çünkü ikinci dil öğrenicileri, sözcükleri bir arada tutan bu kuralların farkında olarak ve hatta bu kurallara özel bir çaba göstererek ikinci bir dili öğrenmeye çalışmaktadırlar (Brooks 1964).

Türkçe sözdiziminin en göze çarpan özelliği, yüklemin tümce sonunda yer almasıdır. Bu özellik, yabancı dil olarak Türkçe öğretiminde yaşanılan sorunların en önemli nedenlerinden biri olarak karşımıza çıkmaktadır (Özkan ve Bağdagül, 2004). Alanyazında özellikle de yabancı dil olarak Türkçeyi öğrenen ve anadili İngilizce olan bireylerin iki dil arasında daha çok karşılaştırma yaptıkları, dahası kendi anadillerinde düşündükleri için yüksek oranda sözdizimsel hatalar yaptıkları belirtilmektedir (Özyürek 2009). Bu anlamda Türkçenin yabancı dil olarak öğretilmesi sürecinde sorun odaklı yaklaşımlara yönelik yapılan araştırmalar oldukça önem kazanmaktadır.

Sorun odaklı yaklaşımlardan biri olan hata analizi yöntemi, ikinci dil öğrenme sürecinin incelenmesi açısından oldukça önemli ipuçları vermektedir. Temelde, öğrenci hatalarının ikinci dil ediniminin altında yatan sürecin anlaşılmasına yardımcı olduğu savı üzerine kurulan bu yöntemin, dil öğretimine farkıı açılardan rehberlik ettiği ifade edilmektedir (Richard, 2015). Nitekim alınyazında hata analizi yönteminin öğretmenlere öğrencinin ikinci dildeki ilerleme düzeyi hakkında bilgi verdiği ve analiz yapma olanağı tanıdığı; dil araştırmacılarına dilin nasıl öğrenildiği konusunda fikir verdiği, yine öğrenenlere ise bireylerin öğrendikleri dilin doğasını tanımada kolaylık sağladığı belirtilmektedir (Khodabandeh, 2007).

Keshavars (2012), hata analizini teorik ve uygulamalı olmak üzere iki açıdan ele almaktadır. Hataların teorik analizi, dil öğrenimindeki süreç ve stratejiler ile hedef dilin ana dille benzerliklerini incelemekte, aynı zamanda da aşırı genelleme, basitleştirme gibi öğrencilerin kullandıkları stratejileri ortaya çıkarmaya çalışmaktadır. Uygulamalı hata analizi ise iyileştirici kurslar düzenleyerek teorik hata 
analizinin bulgularına dayalı uygun materyal ve öğrenme stratejileri geliştirmeyi hedeflemektedir (Keshavarz, 2012).

Dil öğretimini en iyi biçimde anlayabilmek ve bunun sonucunda da öğretimi verimli hâle getirebilmek için öğrencinin zihnindeki süreci anlamak gereklidir. Öğretim sürecinin verimli olup olmadığı ise öğrencilerin üretimi olan hatalar aracılığı ile anlaşılabilmektedir. Diğer bir ifadeyle soyut bir süreç olan dil öğreniminin somutlaştırılması ancak öğrenci hatalarının tespiti ile mümkün olabilmektedir. Bu nedenle bu çalışmada, anadili İngilizce olan ve Türkçeyi yabancı dil olarak öğrenen bireylerin en çok yaptıkları sözdizimsel hataları, hata analizi ve karşılaştırmalı analiz bulgularından yararlanarak belirlemek, bu hataların nedenlerini saptamak ve buna uygun olarak, genelde yabancı dil özelde ise yabancı dil olarak Türkçe öğretmenlerine dil öğretim sürecini daha verimli hâle getirebilecek çözüm önerileri sunmak amaçlanmıştır.

\section{Yöntem}

\section{Araştırmanın Modeli}

Bu çalışma, betimsel modelde desenlenmiş bir özaktarım araştırmasıdır. Özaktarım araştırmalarının verileri, örneklemde yer alan bireylerin kendilerinden bilgi alınarak toplanır. Bu türden çalışmalarda katıımcılardan, anketler aracılığıyla yazılı olarak bilgi alınabileceği gibi, görüşmeler yoluyla sözlü olarak da bilgi toplanabilir (Özdamar, 1999).

\section{Araştırma grubu}

Çalışma, Indiana Üniversitesi Turkish Flagship Programında yabancı dil olarak Türkçe öğrenen ve anadili İngilizce olan A2 seviyesindeki 30 Turkish Flagship öğrencisinin katılımıyla gerçekleştirilmiştir. Uygulama için Indiana Üniversitesi Etik Kurul onayı alınmıştır (Protokol No:1712586128). Uygulama öncesinde katılımcılar veri toplama aracı, uygulama ve uygulama süresi olmak üzere çalışmanın bütün aşamaları hakkında yazılı ve sözlü olarak bilgilendirilmiştir. Tüm katılımcılar, aydınlatılmış gönüllü formunu okuyup imzaladıktan sonra araştırmaya geçilmiştir.

\section{Veri Toplama Araçları}

Öğrenci hatalarını saptamak için öğrencilere "Sorulara Cevap Verme”, "Boşluk Doldurma” ve "Tümceyi Yeniden Yazma" bölümlerinden oluşan bir test uygulanmıştır.

\section{Verilerin Toplanması}

Verilerin toplanmasında alan uzmanlarıyla yapılan görüşmeler sonucunda, Yabancı dil olarak Türkçe öğrenen ve A2 seviyesinde bulunan bireyler için bir test oluşturulmuştur. Uygulama testi hazırlanırken öncelikle bu düzey öğrencileri için kullanılan Indiana Üniversitesi Turkish Flagship programında okutulan Türkçe ders kitapları ayrıntılı bir şekilde incelenmiştir. Yapılan incelemelerle her 
ünitede anlatılan dilbilgisi konuları ve öğretilmesi planlanan söz dizim kalıpları belirlenmiş ve bu konuları kapsayacak şekilde veri toplama aracına son hali verilmiştir. Hazırlanan uygulama testi, her biri 15 sorudan oluşmak üzere "sorulara cevap verme", "boşluk doldurma" ve "tümceyi yeniden yazma" türlerinden oluşturulmuştur.

\section{Verilerin Analizi}

Verilerin analizinde İçerik analizi yöntemi kullanılmıştır. Öğrencilerin yaptığı hatalar öncelikle sıkık ve yüzde cinsinden ifade edilmiş, ardından hatalara ilişkin örnekler verilmiştir. Sözdizimsel hatalar incelenirken, dil içi hatalar ve dil aktarım hataları olmak üzere bir sınıflandırma yapılmıştır. Çalışmanın asıl konusu dil aktarım hataları olduğu için, dil içi hatalar ayrıntıya girilmeden genel olarak yorumlanmıştır.

\section{Bulgular}

Çalışmamızda ilk olarak "sorulara cevap verme" kategorisi ele alınmıştır. Bu kategoride yabancı dil olarak Türkçe Öğrenen bireylerden sorulan sorulara cevap yazmaları istenmiştir. Öğrencilerinin sorulara cevap verme türüne ilişkin yaptıkları hataların genellikle isim hal ekleri, zaman ekleri ve olumsuzluk ekinin yanlış kullanımından kaynaklandığı görülmüştür (Tablo 1).

Tablo 1. "Sorulara Cevap Verme" Türünde Öğrenci Hataları

\begin{tabular}{lllll}
\hline Öğrenci cevapları & Doğru & Yanlış & $\mathbf{n}$ & \% \\
Soru 1 & 11 & 19 & 30 & 36,7 \\
Soru 2 & 10 & 20 & 30 & 33,3 \\
Soru 3 & 8 & 22 & 30 & 26,7 \\
Soru 4 & 2 & 28 & 30 & $\mathbf{6 , 7}$ \\
Soru 5 & 15 & 15 & 30 & 50 \\
Soru 6 & 13 & 17 & 30 & 43,3 \\
Soru 7 & 8 & 21 & 30 & 26,7 \\
Soru 8 & 15 & 15 & 30 & 50 \\
Soru 9 & 9 & 21 & 30 & 30 \\
Soru 10 & 10 & 20 & 30 & 33,3 \\
Soru 11 & 6 & 24 & 30 & $\mathbf{2 0}$ \\
Soru 12 & 3 & 27 & 30 & $\mathbf{1 0}$ \\
Soru 13 & 11 & 19 & 30 & 36,7 \\
Soru 14 & 12 & 18 & 30 & 40 \\
Soru 15 & 14 & 16 & 30 & 46,7 \\
\hline
\end{tabular}

(Soru 4: Hiç bisiklete bindiniz mi?)

Öğrenci yanıtları

Ö3: Evet ben önceden bisiklet binermezdim

Ö7: Evet bisiklet binişdim 


\section{Ö16: Hayır ben hiç bisiklet binmek yok.}

(Soru 11: Günlük hayatınızda Türkçe şarkı dinliyor musunuz?

Öğrenci yanıtları

Ö9: Evet ben Türkçe şarkı dinleyoruz.

Ö14: Evet Türkçe şarkilar dinleyiyorum.

Ö28: Ben hayatımda Türkçe konuşmak istiyorum.

(Soru 12: Herman B Welss kütüphanesinin nerede olduğunu tarif eder misiniz?

Öğrenci yanıtları

Ö1: Kütüphane campusun on tarafısinda.

Ö9: Kütüphane bus stop karşı ustusunde.

Ö23: Kütüphane campus merkezisinin yanısında.

Bunun dışında bazı öğrencilerin dilbilgisel açıdan doğru tümceler üretmelerine rağmen, verdikleri cevapların sorulan soruya yönelik olmamasından kaynaklı hatalar yaptıkları görülmüştür (Soru 7, Ö28 yanıtında olduğu gibi). Burada yapılan hata, gizli hatalara örnek olarak değerlendirilmektedir.

Çalışmamızda ikinci olarak öğrencilerden kendilerine verilen paragraftaki boşlukları parantez içindeki sözcüklere, uygun ekleri getirerek doldurmaları istenmiştir. Öğrencilerin boşluk doldurma türüne ilişkin cevapları incelendiğinde en çok karşılaşılan hataların, zaman ve kişi eklerinin yanlış kullanımından kaynaklanan hatalar olduğu görülmüştür (Tablo 2).

Tablo 2. "Boşluk Doldurma" Türünde Öğrenci Hataları

\begin{tabular}{lllll}
\hline Öğrenci cevapları & Doğru & Yanlıs & $\mathbf{n}$ & $\mathbf{\%}$ \\
Cümle 1 & 4 & 26 & 30 & $\mathbf{1 3 , 3}$ \\
Cümle 2 & 12 & 18 & 30 & 40 \\
Cümle 3 & 11 & 19 & 30 & 36,7 \\
Cümle 4 & 6 & 24 & 30 & $\mathbf{2 0}$ \\
Cümle 5 & 10 & 20 & 30 & 33,3 \\
Cümle 6 & 7 & 23 & 30 & $\mathbf{2 3 , 3}$ \\
Cümle 7 & 13 & 17 & 30 & 43,3 \\
Cümle 8 & 14 & 16 & 30 & 46,7 \\
Cümle 9 & 9 & 21 & 30 & 30 \\
Cümle 10 & 10 & 20 & 30 & 33,3 \\
Cümle 11 & 6 & 24 & 30 & $\mathbf{2 0}$ \\
Cümle 12 & 13 & 17 & 30 & 43,3 \\
Cümle 13 & 11 & 19 & 30 & 36,7 \\
Cümle 14 & 14 & 16 & 30 & 46,7 \\
Cümle 15 & 12 & 18 & 30 & 40 \\
\hline
\end{tabular}


(Cümle 1. Sevgili Helin, Evvelki gün bahçemizde benim doğum (gün) kutladık)

Öğrenci yanıtları

Ö6: Sevgili Helin, Evvelki gün bahçemizde benim doğum...günümüzü.. kutladık. Ö12: Sevgili Helin, Evvelki gün bahçemizde benim doğum...günüsü.. kutladık. Ö13: Sevgili Helin, Evvelki gün bahçemizde benim doğum...günümleri.. kutladık. Ö17: Sevgili Helin, Evvelki gün bahçemizde benim doğum...günü.. kutladık.

(Cümle 4. Emel ile Barış küçük bir dans gösterisi bile. ..(yapmak). Harikaydı!)

Öğrenci yanıtları

Ö2: Emel ile Barış küçük bir dans gösterisi bile...yapayorlar.. Harikaydı!

Ö19: Emel ile Barış küçük bir dans gösterisi bile...yapmışdılar..Harikaydı!

Ö22: Emel ile Barış küçük bir dans gösterisi bile...yaparlar.. Harikaydı!

Ö25: Emel ile Barış küçük bir dans gösterisi bile...yapayordular.. Harikaydı!

(Cümle 6: Ne yazık ki sen yoktun. Zaten herkes........ (sen) sordu.)

Öğrenci yanıtları

Ö4: Ne yazık ki sen yoktun. Zaten herkes...senden.....sordu.

Ö17: Ne yazık ki sen yoktun. Zaten herkes...sene.....sordu.

Ö21: Ne yazık ki sen yoktun. Zaten herkes...senin.....sordu.

Ö22: Ne yazık ki sen yoktun. Zaten herkes...sena.....sordu.

(Cümle 11: Hediye paketini açınca öyle sevindim ki..........! (anlatmak))

Öğrenci yanıtları

Ö1: Hediye paketini açınca öyle sevindim ki...anlatmaz...!

Ö16: Hediye paketini açınca öyle sevindim ki...anlatamayor ben..!

Ö23: Hediye paketini açınca öyle sevindim ki...anlatmadım...!

Ö30: Hediye paketini açınca öyle sevindim ki...anlarmatım..!

Çalışmamızda son olarak öğrencilerden, kendilerine verilen bilgilere göre tümceleri yeniden yazmaları istenmiştir. Öğrencilerin genellikle zamanların Türkçe söz dizilişine ilişkin hatalar yaptıkları görülmüştür (Tablo 3). 
Yabancı Dil Olarak Türkçe Öğrenen Bireylerin Yaptıkları Sözdizimi Hatalarının İncelenmesi

Tablo 3. "Tümceleri Yeniden Yazma" Türünde Öğrenci Hataları

\begin{tabular}{lllll}
\hline Öğrenci cevapları & Doğru & Yanlış & $\mathbf{n}$ & $\mathbf{\%}$ \\
Soru 1 & 13 & 17 & 30 & 43,3 \\
Soru 2 & 9 & 21 & 30 & 30 \\
Soru 3 & 15 & 15 & 30 & 50 \\
Soru 4 & 12 & 18 & 30 & 40 \\
Soru 5 & 15 & 15 & 30 & 50 \\
Soru 6 & 14 & 16 & 30 & 46,7 \\
Soru 7 & 8 & 22 & 30 & $\mathbf{2 6 , 7}$ \\
Soru 8 & 12 & 18 & 30 & 40 \\
Soru 9 & 9 & 21 & 30 & 30 \\
Soru 10 & 10 & 20 & 30 & 33,3 \\
Soru 11 & 11 & 19 & 30 & 36,7 \\
Soru 12 & 13 & 17 & 30 & 43,3 \\
Soru 13 & 5 & 25 & 30 & $\mathbf{1 6 , 7}$ \\
Soru 14 & 9 & 21 & 30 & 30 \\
Soru 15 & 2 & 28 & 30 & $\mathbf{6 , 7}$ \\
\hline
\end{tabular}

(Soru 7: tercih etmek / Ayşe / genellikle / kahve / i̧̧mek)

Öğrenci yanıtları:

Ö11: Ayşe genellikle tercih eder kahve içmesi

Ö17: Ayşe tercih ediyor genellikle kahve içmesini

Ö21: Ayşe tercih etdi genellikle kahve içmeyi

(Soru 13: Anne / oğul / okul / geçen hafta / götürmek)

Öğrenci yanıtları:

Ö10: Geçen hafta annesi oğlusunu okula götürürdi.

Ö27: Annesi oğuluna geçen hafta okulda götürdiler.

Ö29: Oğulunu annesi geçen hafta okulda götürürmuş.

(Soru 15: Gelecek ay / Ali / Ankara / taşınmak / apartman / yeni)

Öğrenci yanıtları:

Ö3: Ali Ankarada yeni apartameninde taşınacekti gelecek ay.

Ö17: Gelecek ay Ali yeni apartmane taşınacak Ankaraya.

Ö21: Ankarayı Ali taşınacak gelecek ay yeni apartmanısına

Tartışma, Sonuç ve Öneriler 
Çalışmamızda ilk olarak Türkçeyi yabancı dil olarak öğrenen bireylerden kendilerine yazılı olarak yöneltilen soruları cevaplamaları istenmiştir. Öğrencilerin cevapları incelendiğinde, yapılan hataların genellikle dilbilgisinin yanlış kullanımından kaynaklı olduğu görülmüştür. Bulgularımızla örtüşür şekilde Nurlu ve Kutlu (2015) tarafından yabancı dil olarak Türkçe öğrenen A1 seviyesindeki Afganlı öğrenciler üzerinde yapılan çalışmada da öğrencilerin sıklıkla dilbilgisel hatalar yaptıkları belirtilmiştir (Nurlu vd. 2015). Yine Bölükbaş ve Yargın (2012) da yabancı dil olarak Türkçe öğrenen Kırgız öğrenciler üzerinde yaptıkları çalışmalarında benzer sonuçlara ulaşmış ve öğrencilerin sıklıkla zaman eklerinin yanlış kullanımından kaynaklanan dilbilgisel hatalar yaptıklarını ifade etmişlerdir (Bölükbaş vd. 2012). Benzer şekilde Büyükikiz ve Hasırcı (2013) tarafından yapılan çalışmada da yabancı dil olarak Türkçe öğrenen öğrencilerin yazılı anlatımları incelenmiş ve öğrencilerin \%31,2 (400) oranında dilbilgisi hatası yaptıkları sonucuna ulaşılmıştır. Yazarlar yapılan dilbilgisi hatalarının, tüm hatalar içerisinde ikinci sırada yer aldığını belirterek bu durumu dilbilgisi kurallarının öğrenciler tarafından yeterince içselleştirilmemesinin ve sınıf içi yazma uygulamalarında öğrencilere bu konuyla ilgili geri dönüt verilmemesinin bir sonucu olabileceği şeklinde yorumlamışlardır (Büyükikiz ve Hasırcı, 2010). Yabancı dilin eksik ya da yanlış öğrenilmesinden kaynaklandığı düşünülen bu hataların yanı sıra çalışmamızda, az da olsa dilbilgisel olarak doğru ancak iletişimin içeriğine uygun olmayan gizli hataların da yapıldığı gözlenmiştir. Bu durumun öğrencilerin yeterince tecrübe kazanmadan hedef dile ilişkin genellemeler yapmaları sonucu ortaya çıkan dil içi aktarımlardan kaynaklandığı düşünülmektedir. Bunun dışında çalışmamızda bazı öğrencilerin dilbilgisel açıdan doğru tümceler üretmelerine rağmen, verdikleri cevapların sorulan soruya yönelik olmamasından kaynaklanan hatalar da yaptıkları görülmüştür. Bu durum yabancı dil öğretimi sürecinde sıklıkla gözlenmektedir. Nitekim Ciğerci (2009) de yabancı dil olarak İngilizce öğrenen Türk öğrenciler üzerinde yaptığı çalışmasında bu süreçte öğrencilerin sorulan soruya yönelik cevaplar veremediklerini belirtmiştir (Ciğerci 2009).

Çalışmamızda ikinci olarak öğrencilerden kendilerine verilen paragraftaki boşlukları doldurmaları istenmiştir. Öğrencilerin boşluk doldurma türüne ilişkin cevapları incelendiğinde en çok karşılaşılan hataların, zaman ve kişi eklerinin yanlış kullanımından kaynaklanan hatalar olduğu görülmüştür. Kozan (2017) da yaptığı çalışmasında yabancı dil olarak Türkçe öğrenen Rus öğrencilerin çoğunlukla isim hâl eklerini yanlış kullandıklarını belirtmiştir (Kozan 2017). Yine Şahin (2013) tarafından yabancı dil olarak Türkçe öğrenen farklı ülke öğrencileri üzerinde yapılan çalışmada da yapılan hataların ülkeden ülkeye farklılık gösterdiği sonucuna ulaşılmıştır (Şahin 2013). Çerçi ve arkadaşları (2016) ise Gaziantep TÖMER'de eğitim gören ve A1, A2, B1, B2 ve C1 seviyesindeki Türkçe öğrenen yabancı öğrencilerin yazılı anlatımlarını inceledikleri çalışmalarında öğrencilerin sözcük seçiminden kaynaklanan hatalar yaptıklarını ve yapılan hata oranının da kur seviyelerine göre farklılık gösterdiğini belirtmişlerdir (Çerçi, Derman ve Bardakçı, 2013). 
Çalışmamızda son olarak öğrencilerden, kendilerine verilen bilgilere göre tümceleri yeniden yazmaları istenmiştir. Öğrencilerin genellikle Türkçe söz dizilişine ilişkin hatalar yaptıkları görülmüştür. $\mathrm{Bu}$ durumun, Türkçe ve İngilizcenin farklı sözdizimi yapısına ait olmasından kaynaklandığı düşünülmektedir. Nitekim bu düşünceyi destekler şekilde Huang (2001) da anadili Çince olan ve yabancı dil olarak İngilizce öğrenen bireylerin tümce üretirken genellikle Çince sözdiziminin etkisinden kurtulamadıkları ve bu nedenle de dil aktarım hataları yaptıklarını belirtmiştir (Huang 2001). Benzer şekilde Benzer şekilde Adalar-Subaşı (2010) tarafından TÖMER'de yabancı dil olarak Türkçe öğrenen Arap öğrencilerin kompozisyonlarının incelendiği çalışmada da, öğrencilerin "yüklem"in yanlış kullanılmasından kaynaklı söz dizimi hataları yaptıkları belirtilmiş ve bu durum Arapça cümle yapısının etkisi ile ilişkilendirilmiştir (Adalar-Subaşı, 2010). Huang (2001) ve Adalar- Subaşı (2010)' nı destekler şekilde Şahin (2013) de yabancı dil olarak Türkçe öğrenen farklı anadili konuşurlarından Özbek, Kazak ve Tatar öğrencilerin Rus öğrenciler gibi, Rusçanın sözdizimi yapısına uygun cümleler kurduklarını belirtmiş ve bu durumu da belirli bir derecede anadillerinde konuşsalar bile Rusça eğitim aldıkları için Rusça düşünmeleri ile ilişkilendirmiştir (Şahin 2013).

Sonuç olarak yabancı dil olarak Türkçe öğrenen ve anadili İngilizce olan bireylerin, kendi anadillerinde olmayan Türkçe yapıları ve sözdizimini öğrenmede güçlük çektikleri görülmüştür. Bu nedenle daha geniş örnek gruplarında yapılacak karşılaştırmalı analiz ve hata analizi çalışmalarıyla, öğrencilerin en çok yaptıkları hatalar belirlenebileceği ve buna yönelik farklı öğretim tekniklerinin geliştirilebileceği düşünülmektedir.

\section{Kaynaklar}

Adalar-Subaşı, D. (2010). TÖMER'de yabancı dil olarak Türkçe öğrenen Arap öğrencilerin kompozisyonlarında hata analizi. Dil Dergisi, 148, 7-16.

Atabay, N., Özel,S., \& Çam, A. (1981). Türkiye Türkçesinin sözdizimi. Ankara: Türk Dil Kurumu Yayınları.

Bölükbaş, F. ve Yargin, A. (2012). Error analysis in usage of basic tenses in Turkish by Kirgiz students. Journal of Studia uralo-altaica,49, 143-51.

Brooks, N. (1964). Language and language learning, theory and practice. San Diego: Harcourt, Brace \& World Publish.

Büyükikiz, K.K. ve Hasırcı, S.(2013). Yabancı dil olarak Türkçe öğrenen öğrencilerin yazılı anlatımlarının yanlış çözümleme yaklaşımına göre değerlendirilmesi. Ana Dili Eğitimi Dergisi, 1(4), 51-62.

Ciğerci, A.E. (2009). Ingilizcenin yabancı dil olarak öğretimi bağlamında hata çözümleme denemesi. YayınlanmamışYüksek Lisans Tezi, Ankara Üniversitesi Sosyal Bilimler Enstitüsü, Ankara.

Çerçi, A., Derman, S. \& Bardakçı, M. (2016). Yabancı dil olarak Türkçe öğrenen öğrencilerin yazılı anlatımlarına yönelik yanlış çözümlemesi. Gaziantep University Journal of Social Sciences, 15(2), 695-715.

Gönülal, T. (2012). A correlation study of the relationship between syntactical accuracy, lexical accuracy and the quality of Turkish EFL student writing. Master of Degree Thesis. Ohio State University, Columbus.

Huang, L.S. (2001). Knowledge of English collocations: an analysis of Taiwanese EFL learners, Texas Papers in Foreign Language Education. 
Kang, M. ve Chang, S. (2014). An analysis of lexical errors of Korean language learners. some American college learners' case. Pan-PasificAssociation of Applied Linguistics, 18(2), 93-110.

Keshavarz, M.H. (2012). Contrastive analysis \& error analysis. Tehran: Rahnama Press.

Khodabandeh, F. (2007). Analysis of students' errors: the case of headlines. The Asian ESP Journal, 3, 6-21.

Kozan, O. (2017). Yabancı dil/çeviri eğitiminde karşıtsal çözümleme: biçim-işlev-anlam üçlüsü. Dil Dergisi, 168, 65-81.

Llach, M. (2011). Lexical errors and accuracy in foreign language writing. Bristol: Multilingual Matters

Nurlu, M. ve Kutlu, A. (2015). Türkçenin yabancı dil olarak öğretiminde temel seviye a1 yazma sorunları: Afganistan örneği. Kara Harp Okulu Dergisi, 25, 67-87.

Özdamar, K. (1999). Paket programlar ile istatistiksel veri analizi (2.Baskı). Eskişehir: Kaan Kitabevi.

Özkan, F. ve Bağdagül, M. (2004). Yabancı dillerin Türkçenin söz dizimi üzerindeki etkisi. Bilig, Türk Dünyası Sosyal Bilimler Dergisi, 30, 95-139.

Özyürek, R. (2009). Türk devlet ve topluluklarından Türkiye üniversitelerine gelen Türk soylu yabancı uyruklu öğrencilerin Türkçe öğrenimlerinde karşılaştıkları sorunlar. Journal of Turkish Studies, 4, 1819-62.

Richards, J.C (2015). Error analysis: perspectives on second language acquisition. Abingdon: Routledge Publication.

Şahin, E. (2013). Yabancı dil olarak Türkçe öğrenen öğrencilerin yazılı anlatımlarındaki ek yanlışları. Tarih Okulu Dergisi, 6, 433-449.

\section{Extended Abstract}

Introduction

As it is well known, language is central in our lives. In our global society, this is the case not only of our mother tongue, but also of other second languages required to communicate within the international society in specialized contexts. In recent years, foreign language education has been focusing on learning styles. Because learning a new language is a difficult feat for which people have to develop a complex set of linguistic skills, including encoding the words of the new language, learning syntactic structure, and integrating the resulting representations with existing language knowledge. Especially in adulthood, second language (L2) learning process is notoriously difficult as opposed to first language (L1) acquisition or child L2 acquisition.

Unlike many other languages, syntax in Turkish is different. English and Turkish are of different language groups in terms of head-last or head-first, SVO or SOV, subject drop or non-drop languages. Therefore, especially English native speaking learners of Turkish have difficulties in particular with the word order and grammatical aspects of Turkish syntax.

Errors are a naturel and inevitable part of the language learning process. Although many recent studies have been conducted (but mostly on English as the target language) using an error analysis approach (Gonual, 2012; Llach, 2011), few studies (Kang and Chang, 2014) have adopted this approach to less commonly taught languages. This is unfortunate, because an error analysis approach can be highly useful in examining the acquisition of agglutinating languages such as Turkish in which morphology and syntax have been shown to be a source of great difficulty. On the other hand, it is frequently stated that individuals who learn Turkish as a foreign language and native speakers of English make more comparisons between two languages, and they make more often morphologic and syntactic errors by thinking in their mother tongue. In this sense, studies on problemoriented approaches in teaching Turkish as a foreign language become important.

The error analysis method, which is one of the problem-oriented approaches, provides an important clue for the second language learning process. Therefore, in this study, it is aimed to determine the most common syntactic errors by English native speaker learners of Turkish as a foreign language by using error analysis and comparative analysis findings.

\section{Method}

This study was conducted on 30 native speakers of English who are A2 level students at Indiana University Program of Turkish Flagship. For determining student errors, the test consisting of "Answering to Questions", "Gap-Filling" and "Re-writing the Sentences", was implemented. 


\section{Result and Discussion}

Syntax has been shown to be an area of persistent difficulty for foreign language learners. It is no different for English native speaking learners of Turkish. Indeed, English native speaking learners of Turkish have difficulties especially with the grammatical aspects of Turkish syntax (Gonulal, 2012). In line with previous Turkish studies (Şahin, 2013; Bölükbaş, 2012) we found that some of the errors detected in this study can likely be attributed to the fact that Turkish is agglutinative language while English is to a large extent isolating. In addition, the roots of some of other grammatical errors such as subject-verb agreement and singular/plural errors might be attributed to negative transfer between English and Turkish. To sum up, in this study it was seen that students mostly made syntax errors which kind of morphological and grammatical and also word order. 